\title{
Las luchas que educan: La Educación Ambiental de Base Comunitaria y las Consultas Populares en el conflicto minerio en Colombia.
}

\section{As lutas que educam: A Educação Ambiental de Base Comunitária e as Consultas Populares no Conflito de Mineração na Colômbia.}

\author{
Bárbara Pelacani ${ }^{1}$; Renzo Alexander García Parra² ; Jorge Mario Vera Rodríguez ${ }^{3}$; \\ Celso Sánchez ${ }^{4}$
}

1 Doctoranda en Psicossociologia de Comunidades y Ecologia Social en la Universidad Federal de Rio de Janeiro (UFRJ), Profesora de la Universidad Federal Rural de Rio de Janeiro (UFRRJ), Rio de Janeiro, Brasil - barbara.pelacani@gmail.com / ORCID

2 Master en Territorio, Conflicto y Cultura en la Universidad del Tolima, Vicepresidente de la Asociación de Biólogos de la Universidad del Tolima, Cofundador Comité Ambiental en Defensa de la Vida de Colombia. Ibagué, Tolima, Colombia email / ORCID

3 Doctorando en Planificación y Manejo Ambiental de Cuencas Hidrográficas, Investigador del Grupo Interdisciplinario de Estudios sobre el Territorio, de la Universidad del Tolima, Ibagué, Colombia - jmverar@ut.edu.co / ORCID 0000-00015411-4140

4 Professor del Pós Grado en Educación en la Universidad Federal del Estado de Rio de Janeiro (UNIRIO), Cordinador del Grupo de Estudios en Educación Ambiental desde el Sur (GEASur), Rio de Janeiro, Brasil - email / ORCID

\section{Palabras-clave:}

Educación Ambiental.

Comunidades. Ecología

Política. Lucha

Socioambiental.
RESUMEN: En este trabajo nos proponemos abordar las Consultas Populares celebradas en casos de conflictos sociales y ambientales en Colombia como una posibilidad de acción participativa de las comunidades en la lucha por la justicia socioambiental. Presentamos acá la confluencia de la Educación Ambiental de Base Comunitaria en diálogo con el campo de la Ecología Política. Analizaremos los casos en que se aplicó la Consulta Popular en las ciudades de Ibagué y Cajamarca, departamento del Tolima, Colombia, referente a la actuación del movimiento ambiental a frente al conflicto por el proyecto minero La Colosa de la multinacional Anglo Gold Ashanti. Buscamos comprender cómo la lucha social y ambiental puede ingresar al campo político y convertirse en un instrumento de acción comunitaria. Identificamos en las luchas los sujetos involucrados, tanto el movimiento ambientalista junto a la Universidad del Tolima, como los ciudadanos que lo apoyan. Pensar nuevas formas de educación ambiental desde los saberes de los pueblos y sus territorios en disputa se pone en marcha con la práctica para ampliar los horizontes acerca de la resistencia con las empresas neoextrativistas en la América Latina y hacer complejo el tema de los conflictos ambientales es lo que motiva a los autores en dicha praxis.

RESUMO: Neste artigo, propomos abordar as consultas populares realizadas em casos de conflitos sociais e ambientais na Colômbia como uma possibilidade de ação participativa das comunidades na luta pela justiça socioambiental. Apresentamos aqui a confluência da Educação Ambiental Comunitária em diálogo com o campo da Ecologia Política. Analisaremos os casos em que a Consulta Popular foi aplicada nas cidades de Ibagué e Cajamarca, do departamento de Tolima, Colômbia, referindo-se à atuação do movimento ambientalista diante do conflito pelo projeto de mineração de La Colosa da multinacional Anglo Gold Ashanti. Buscamos entender como a luta social e ambiental pode ingressar no campo político e se tornar um instrumento de ação comunitária. Nas lutas, identificamos os sujeitos envolvidos, tanto o movimento
Palavras-cheve: Educação Ambiental. Comunidades. Ecologia Política. Luta Socioambiental. 
ambientalista junto com a Universidade de Tolima, como os cidadãos que o apoiam. Pensar em novas formas de educação ambiental a partir do conhecimento dos povos e de seus territórios em disputa se põe em marcha com a prática de ampliar os horizontes da resistência com empresas neo-extrativistas na América Latina e tornar complexa a questão dos conflitos ambientais é o que motiva os autores nessa práxis.

\section{INTRODUCCIÓN}

La Educación Ambiental (EA) es una apuesta por la vida. Una mirada al aprendizaje que ocurre en el encuentro con causas ambientales. Su configuración como conocimiento socioambiental revela su potencia: comprender las desigualdades sociales a partir de los conflictos. Al identificar los problemas e impactos que ocurren en la naturaleza, abrimos ventanas para observar las opresiones sobre los sujetos. En este punto, la relación inseparable entre la sociedad y la naturaleza justifica tal afirmación. Toda explotación y subyugación del medio ambiente es también un proceso de expropiación y violencia contra las comunidades. El modelo actual de desarrollo político y económico profundiza el modelo colonial instituido en la modernidad con base en la explotación de territorios y la indigencia de la vida, instituyendo la crisis socioambiental que estamos viviendo. Al resistir a tales procesos, la Educación Ambiental se convierte en un poder para buscar la autonomía de los pueblos.

La búsqueda por transformaciones que conducen a la emancipación humana se produce al observar las posibilidades históricas. Para superar la crisis y alcanzar un nuevo nivel de relación sociedad-naturaleza, Loureiro $(2019$, p.178) hace la apuesta por la "acción colectiva y organizada, el diálogo sincero y abierto al otro que está en la condición de expropiado y oprimido por el capitalismo, para producir un nuevo tipo de sociedad y, por lo tanto, de personas.". Complementando el significado de EA que nos orienta, el autor afirma que "educar significa humanizarse en procesos sociales intencionados, (...). La crítica se hace necesaria para que podamos superar las relaciones alienadas, vivir libremente y apreciar la belleza de la vida "(ibidem).

Tratamos con la EA en sus múltiples identidades, lo que la configura como un campo en disputa (Layrargues y Lima, 2014). Nuestro objetivo es plantear una educación basada en la comunidad, desde una perspectiva crítica al sistema productivo de desarrollo. Una EA que mire la transformación social y considere los conflictos sociales y ambientales como un punto central para comprender la crisis actual, que Observe el conflicto desde el punto de vista epistemológico, político, social, ambiental y económico. Sabemos que en el encuentro entre el ser humano y la naturaleza trata de un ser humano que no es genérico y neutral, lleva consigo sus identidades de clase, género y raza. Las acciones de distintos sujetos sociales producen diferentes impactos. Por lo tanto, la perspectiva de la Educación Ambiental de Base 
Comunitaria (EABC) (Pelacani, 2018; Pelacani et. al. 2019; Sarria et. al., 2018) identifica que no es posible considerar los problemas ambientales apartados de los sociales. Al tratar de comprender la crisis socioambiental, además de la cuestión económica, uno debe considerar la desigualdad social que prevalece en las condiciones de acceso a los bienes naturales. Considerando que un pescador artesanal y una refinería de petróleo no pueden comprometerse de manera similar a cuidar la calidad del agua en una cuenca hidrográfica. Así como los impactos de las actividades intensivas del agronegocio son distintos de los efectos de la agricultura campesina en el territorio, por ejemplo.

Por lo tanto, es importante preparar, junto con la comunidad, una planificación y construcción de una sociedad democrática. En EABC se debe preconizar la intervención social de los territorios, en lo que dice respecto a los derechos humanos, con la valorización de la participación de organizaciones de la sociedad, especialmente los movimientos sociales, en los espacios democráticos. La búsqueda por estas integraciones como utopía socioambiental parte de la comprensión de las luchas planteadas en los territorios para establecer libertades y fortalecer seres autónomos por los derechos colectivos en el ejercicio político. (PELACANI et. al., 2019, p. 35)

La perspectiva de una Educación Ambiental de Base Comunitaria considerada por Pelacani et al (219) en diálogo con la propuesta teórica de Sarria et. al. (2018), se propone problematizar el contexto geopolítico latinoamericano y el legado de las luchas sociales de América Latina como base político-teórico-metodológica para pensar una Educación Ambiental no-norte-eurocéntrica. Así como la visión de la Educación Ambiental como una herramienta de gestión popular de los recursos naturales para la Justicia Socioambiental. Desde las comunidades miramos la crisis, reconociendo la realización de sus propuestas de acción, con otras ideas pedagógicas. Buscamos implementar estrategias para trabajar la educación ambiental con las comunidades a través de un diálogo entre el saber popular y el saber científico, entre el saber teórico y el saber práctico. Afirmamos que la comunidad organizada y que actúa políticamente es más resistente porque es más consciente de los bienes naturales de su territorio (PELACANI, 2018).

Finalmente, es importante mencionar el carácter político de la educación ambiental
comunitaria, en tanto posibilita que las personas y organizaciones que habitan los
territorios, sean capaces de tomar decisiones pertinentes frente a lo ambiental y a la
educación. Este carácter político se hace evidente también en la manera como las
comunidades se han organizado en diferentes lugares de América Latina, lo cual ha
generado movimientos sociales de resistencia, protesta y defensa del ambiente, de
los territorios y de la vida en general. (SARRIA, el. al., 2018. p. 64)

LA EABC interpela la Educación Ambiental Hegemónica que tiene en su perspectiva prácticas conservadoras y retrógradas. Sus propuestas son individuales y parten de la culpabilidad de los individuos. Tal concepción difunde la falacia de la culpa de los pobres como promotores de la degradación ambiental. Lo que es más sorprendente, ya que estos grupos son los más afectados por la crisis, los pobres serán culpados de la contaminación, del 
desperdicio y de la apropiación indebida de bienes naturales (MARTINEZ ALIER, 2011). Partiendo de este principio de opresión de clase, la perspectiva conservadora de la EA tendrá como fórmula para superar este hecho la necesidad de buscar la protección de la flora, la fauna y otros bienes naturales, vistos como recursos. Basado en la ruptura de la relación sociedad-naturaleza, producirá una educación para conservar dicho sistema, con un esfuerzo para despolitizar la cuestión ambiental y reducirla a soluciones de orden técnico o gestión económica. La EA conservadora no tiene en cuenta la distribución desigual de los riesgos y daños ambientales que recaen en los grupos sociales y grupos étnicos, así como la forma en que los beneficios ambientales del desarrollo se concentran en los grupos sociales más ricos (LAYRARGUES, 2004).

Desde la EABC comprendemos que algunos sujetos sociales, como las empresas transnacionales y los gobiernos son responsables por generar impactos socioambientales planteando el desarrollo capitalista, centrado en el crecimiento económico. Con eso buscamos analizar la relación sociedad-naturaleza desde la perspectiva de relaciones de poder desiguales, que podemos identificar al analizar los conflictos socioambientales. Donde perspectivas de ambiente diversas van a representar distintas formas de uso de la naturaleza, donde los sujetos más fuertes ejercerán una dominación (ACSELRAD, 2010).

\begin{abstract}
Los conflictos ambientales estallan cuando se cuestiona la legitimidad de ciertas formas de apropiación del espacio y es contestada con alegación de la ocurrencia de los efectos interactivos no deseados de una práctica espacial que se superpone a otras. Por lo tanto, se denuncia la ausencia o la ruptura de compatibilidad entre ciertas prácticas espaciales, poniendo en cuestión la forma de distribución del poder sobre los recursos del territorio. (ACSELRAD, 2010. p.2)
\end{abstract}

Desde la Economía Ecológica el origen de los conflictos ambientales se interpreta como producto del creciente metabolismo social de los países económicamente más desarrollados, quienes demandan progresivas cantidades de materiales, agua y energía, y generan gran cantidad de residuos contaminantes, lo cual tiene efectos nocivos y severos sobre las comunidades y los ecosistemas (MARTÍNEZ ALIER, 2008, 2011; MARTÍNEZ ALIER \& ROCA JUSMET, 2013).

Esta mirada se complementa con la perspectiva de la Ecología Política en que se asumen los conflictos ambientales como conflictos ecológico distributivos (MARTíNEZ ALIER, 2011 y 2010; PÉREZ-RINCÓN, 2010; LEFF, 2003) que surgen de las relaciones de poder, en el marco de los procesos de apropiación, usufructo material y apropiación simbólica del ambiente, por lo que el choque se da entre lenguajes de valoración (TOLEDO, 2008; MARTÍNEZ ALIER, 2008); en este sentido, los conflictos ambientales son mucho más que disputas por la propiedad de "recursos". 
Para Escobar (2014) los conflictos ambientales son conflictos ontológicos en los que se enfrentan cosmovisiones o visiones de mundo distintas, aunque no necesariamente antagónicas; estas se agencian a través de prácticas concretas, por lo que son en realidad mundos en movimiento y no meras representaciones mentales, son mundos que tienen expresiones materiales e inmateriales en los territorios, el cual, el geógrafo brasileño de relevancia internacional Milton Santos significa de la siguiente manera:

\begin{abstract}
El territorio no es apenas el resultado de la superposición de un conjunto de sistemas naturales y un conjunto de sistemas de cosas creadas por el hombre. El territorio es la tierra más la población, es decir, una identidad, el hecho y el sentimiento de pertenecer a aquello que nos pertenece. El territorio es la base del trabajo, de la residencia, de los intercambios materiales y espirituales y de la vida, sobre los cuales él influye. Cuando se trata sobre territorio se debe, pues, desde luego, entender que se está hablando sobre el territorio usado, utilizado por una población dada. (SANTOS, 2000. p. 96-97)
\end{abstract}

La Ecología Política como vertiente de pensamiento y movimiento ambientalista reconoce la actual degradación ambiental y los potenciales riesgos a los que se enfrentan las comunidades en los territorios por la devastación de los bienes ambientales y reivindica nuevas formas de relación entre lo humano y lo no humano, concibiendo el planeta tierra como un ser vivo. Estas concepciones la ponen en diálogo con la EABC en perspectiva de leer los conflictos ambientales en Colombia y orientada al fortalecimiento de la acción del movimiento popular en el Tolima.

\title{
CONSULTA POPULAR: CONFLICTOS Y ACTUACIÓN EN EL TOLIMA
}

El departamento del Tolima, por su riqueza ambiental y su posición geográfica estratégica (Figura 1), se ha convertido en una potencial fuente de extracción de bienes naturales para las empresas nacionales y extranjeras que buscan maximizar sus ganancias aprovechando la carencia de rigurosidad, deficiencias legales y vacíos institucionales que impiden garantizar la protección y conservación de áreas de importancia ambiental para el departamento y la nación. Así, buena parte de las áreas de importancia ambiental especial se encuentran amenazados por la potencial implementación de proyectos mineros, de explotación de hidrocarburos no convencionales mediante la técnica de fracturamiento hidráulico (fracking), hidroeléctricas, cultivos de palma y ZIDRES, los cuales son potencialmente negativos a nivel ecológico y social (Vera et al 2019). 
Ensino, Saúde e Ambiente - Número Especial, pp. 331-352, Junho. 2020

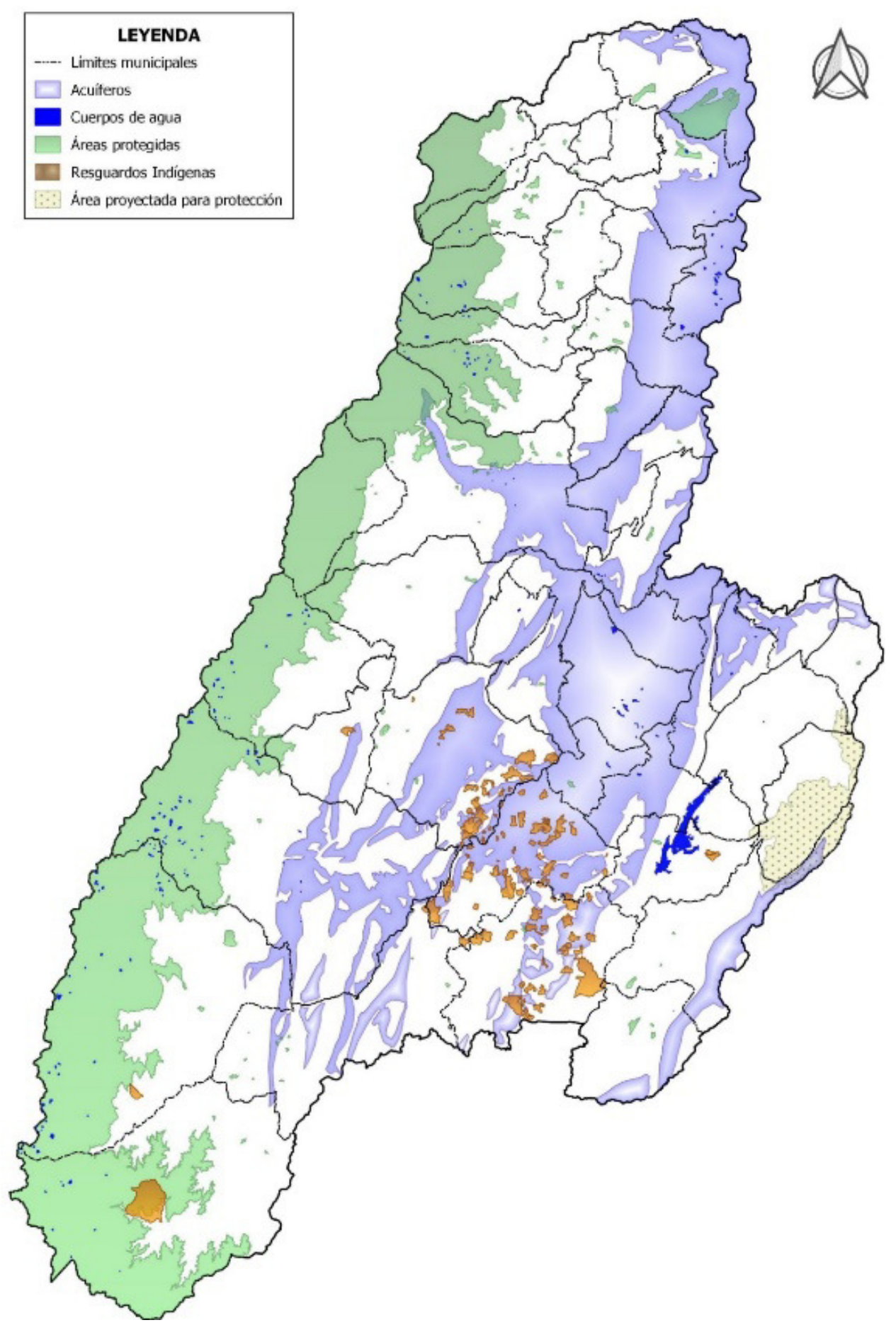

Figura 1. Áreas de importancia ambiental en el Departamento del Tolima

Fuente: Vera et al, Atlas de Conflictos Ambientales del Tolima (2019).

Ello genera conflictos potenciales entre lo que en este trabajo se denomina ordenamiento del territorio del Tolima desde la perspectiva del modelo de desarrollo hegemónico y el ordenamiento ambiental que se ha estructurado a través de áreas declaradas o en proceso de declaratoria como protegidas, acuíferos y resguardos indígenas (Figura 2). 
Ensino, Saúde e Ambiente - Número Especial, pp. 331-352, Junho. 2020

\section{LEYENDA}

-.-- Límites municipales

Áreas de interés para megaproyectos

Relleno sanitario

$\lambda_{1}$ Minas

Proyectos hidroeléctricos

Solicitudes mineras vigentes Tolima (abril 2017)

Titulos mineros vigentes Tolima (abril 2017)

Hidrocarburos no convencionales

Megaproyectos agroindustriales

Areas potenciales para Zidres

Zonas Aptas para palma aceitera

Aptitud Alta

Aptitud Media

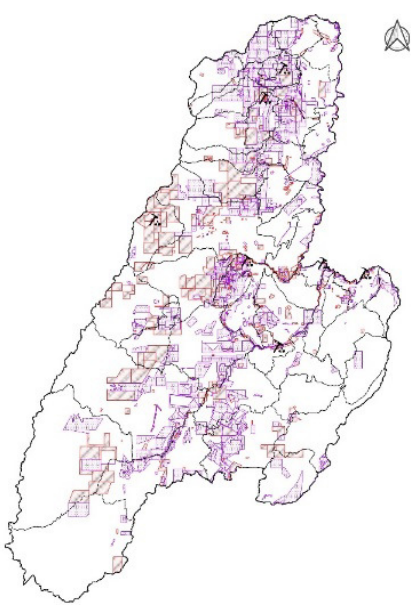

a) Minería

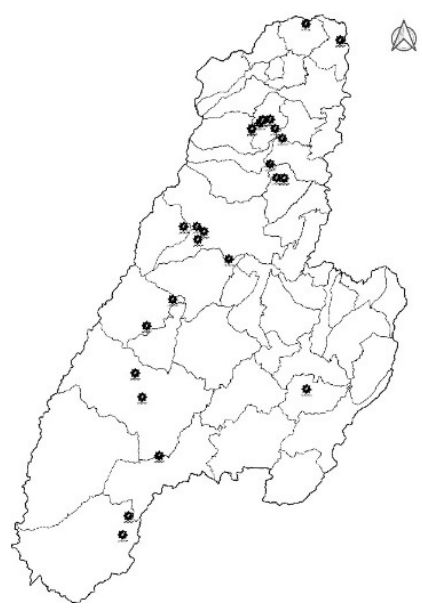

c) Hidroeléctricas

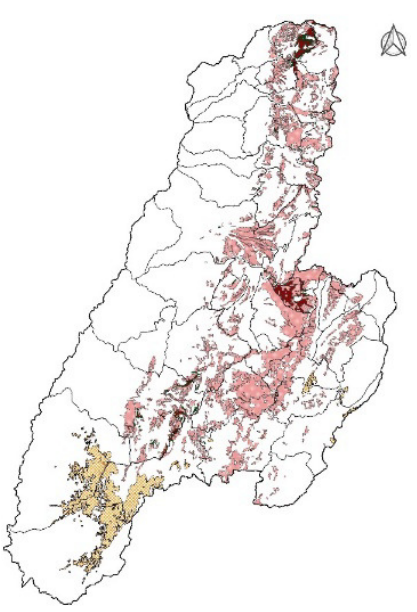

d) Palma aceitera y ZIDRES

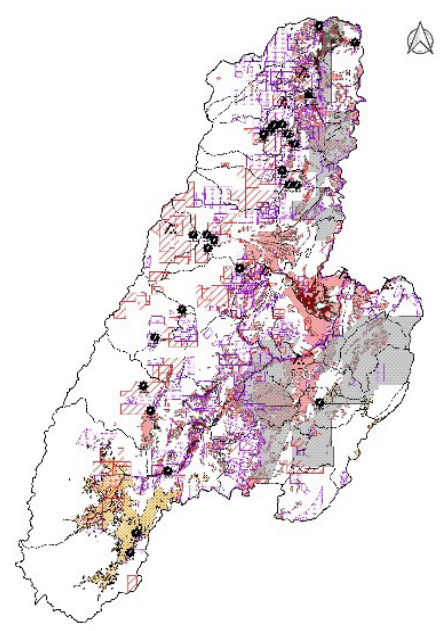

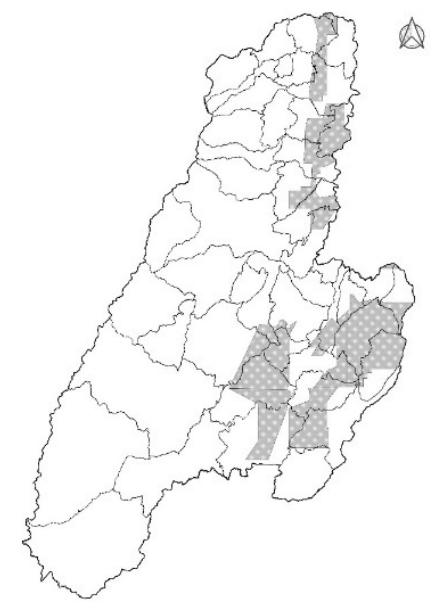

b) Hidrocarburos no convencionales

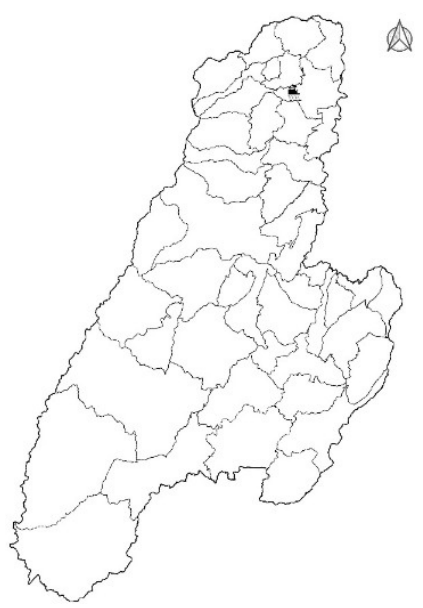

e) Rellenos sanitarios

\section{f) Consolidado de proyectos}

Figura 2. Áreas de interés para proyectos mineros, hidrocarburos no convencionales, hidroeléctricas, palma aceitera, Zidres y rellenos sanitarios en el departamento del Tolima.

Fuente: Vera et al, Atlas de Conflictos Ambientales del Tolima (2019) 
Cabe señalar que, independientemente de la existencia de un área de interés ambiental efectivamente amenazada por el extractivismo, es usual que la población tenga una alta percepción de riesgo debido a diversos factores como la falta de información por parte del gobierno y las empresas, pero sobre todo, casos en los que los peores temores se hicieron realidad como la mina Yanacocha en Perú o El Cerrejón en la Guajira; rellenos sanitarios como Doña Juana y Navarra en Colombia, los efectos del fracking en EE.UU. y la prohibición de este en buena parte de Europa, los impactos de la deforestación para la implementación de palma aceitera en Nigeria, Congo e Indonesia; el problema no resuelto de la concentración de la propiedad de la tierra y la desastrosa experiencia de las hidroeléctricas El Quimbo e Hidroituango en Colombia (Vera et al 2019).

El extractivismo ha generado cambios significativos en términos políticos y sociales en las comunidades, quienes en gran medida han resignificado o revalorado sus territorios y cobran cada vez mayor capacidad de organización, interlocución, movilización y acción política, en respuesta a la implementación de proyectos percibidos negativamente. Esta productividad social, territorial, institucional y jurídica del conflicto ambiental (Merlinsky, 2013), se evidencia en el surgimiento de nuevos liderazgos al margen de los partidos y organizaciones políticas tradicionales. De igual forma, la población ha optado por organizarse y recurrir a mecanismos de lucha y movilización tales como plantones, cabildos abiertos, acciones jurídicas (tutelas, acciones populares, etc.), mecanismos de participación (consultas populares) y la promulgación de acuerdos municipales que restringen la implementación de proyectos mineros a gran escala en los municipios, así como escenarios de formación ambiental popular (Figura 3).

Destacamos aquí experiencias como la creación de comités veredales y veedurías, que junto con los Comités Ambientales municipales y el departamental promueven el mecanismo de la Consulta Popular o Acuerdos Municipales que invocan preceptos constitucionales como el principio de precaución y prevención para restringir el desarrollo de proyectos extractivos en sus territorios; la declaratoria de áreas protegidas y el fortalecimiento del sector rural y la vocación agrícola de os territorios; movilizaciones como la Marcha Carnaval en Defensa de la Vida que llega a su undécima edición y se ha constituido en la movilización ambiental más grande en la historia del Tolima; procesos de formación ambiental popular convocados por el Comité Ambiental del Tolima y apoyados por la Universidad del Tolima a través de la Cátedra Ambiental "Gonzalo Palomino Ortiz” y en los que participan más de 1000 personas cada semestre en sus tres niveles (Vera et al 2019). 
-.-- Límites municipales

\section{LEYENDA}

Organización social

Comité Ambiental constituido

Comité en proceso de formación

Formas de manifestación y acción social

Acuerdo municipal que restringe la minería a gran escala

Audiencias públicas y cabildo abierto

Bloqueo de vías

Consulta Popular

Iniciativa de Consulta Popular aprobada

Iniciativa de consulta popular negada

Marcha Carnaval

Negativa de licencia social en audiencia pública

Veeduría minero-ambiental

Causas de la movilizacion social

$\square$ Hidroeléctricas

Relleno sanitario

Minería metálica

Minería no metálica

Explotación petrolera

Minería de material de arrastre

Minería metálica e hidrocarburos

Minería metálica e hidroeléctricas

Hidrocarburos no convencionales

Minería, hidrocarburos y relleno sanitario

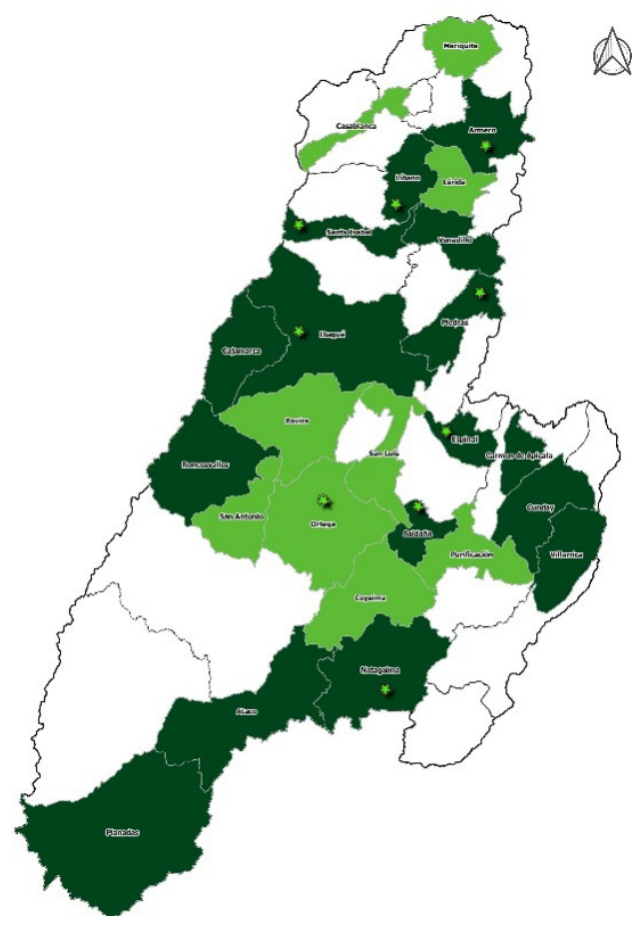

a) Procesos de organización a

nivel municipal

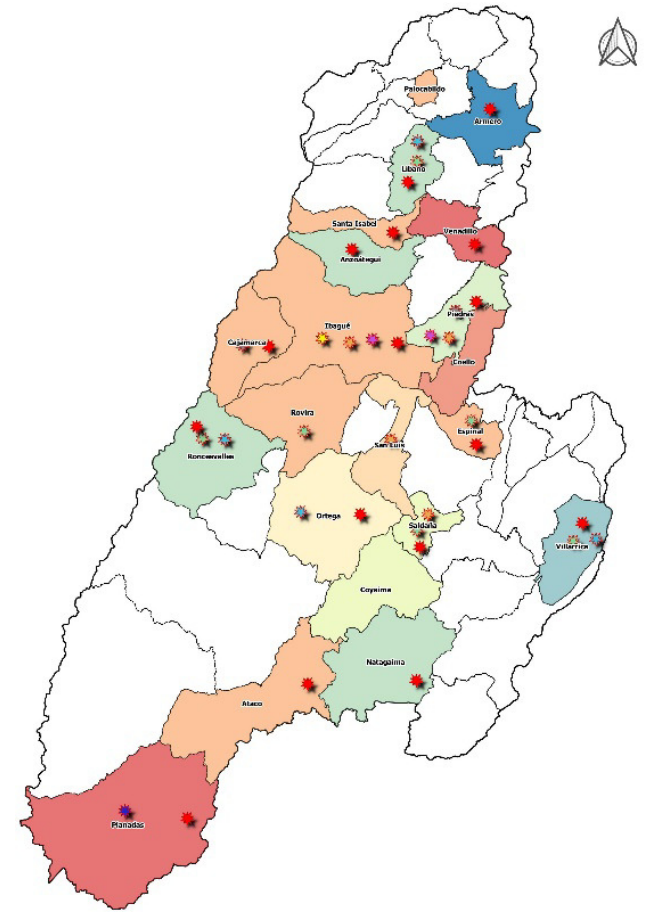

b) Formas de movilización y acción social

Figura 3. Procesos de organización, movilización y acción social ambientalista a nivel de municipios en el departamento del Tolima

Fuente: Vera et al, Atlas de Conflictos Ambientales del Tolima (2019)

Aunque las comunidades implementan acciones diversas y complementarias que les permiten avanzar en sus procesos de defensa territorial frente a los proyectos minero- 
energéticos, hay que resaltar, como dice Dietz (2018), que las consultas populares son una de las estrategias más importantes de estos procesos, asumidas por el movimiento ambiental del Tolima para blindar los territorios frente a las amenazas del extractivismo y que han constituido al movimiento ambiental del Tolima en referente de organización, movilización y acción política a nivel nacional y en fuente de motivación para otros procesos de defensa territorial, por los significativos logros obtenidos (Vera \& Moreno, 2017).

El recurrir a estos mecanismos surge como una acción de rechazo a la contaminación que generan los emprendimientos minero-energéticos, el saqueo de los bienes comunes naturales y el despojo territorial que connaturalmente se encuentran asociados a estos proyectos. De igual forma se puede leer en los discursos de las organizaciones defensoras del agua, la vida y el territorio, una relación entre el extractivismo y las problemáticas del cambio climático, la degradación ambiental, la pérdida de biodiversidad, la afectación de los sistemas de producción agropecuaria, la destrucción del tejido social y la disminución en la calidad de vida de las comunidades.

En cuanto a movilización social, como se observa la convocatoria a Consultas populares como una de las principales formas de movilización que restringen la minería a gran escala. Las Consultas Populares son asumidas comunitariamente como mecanismos de participación directa que permiten defender los derechos económicos, ambientales, sociales y culturales de las generaciones presentes y futuras. Son un proceso similar a la "Consulta Previa, Libre e Informada" contenida en el Convenio Internacional para la Protección de los Pueblos Indígenas de la Organización Internacional del Trabajo (OIT), sin embargo, hay que señalar que las consultas populares tienen un carácter participativo más amplio que recoge todos los sectores sociales que habitan los territorios y un soporte Constitucional, legal y jurisprudencial diferente.

\section{CONSUltas POPULARES Y ACCIÓN POLÍtica FRENTE AL PROYECTO MINERO "LA COLOSA"}

La Colosa, uno de los megaproyectos mineros más ambiciosos del país, ubicado en el municipio de Cajamarca y que se encontraba en fase exploratoria en cabeza de la multinacional sudafricana Anglo Gold Ashanti y que por sus más de 28 millones de onzas de oro es considerado como el más grande yacimiento aurífero hallado en los últimos años en todo el mundo. Dicho proyecto desde sus inicios en el año 2007 despertó una fuerte reacción de rechazo por parte de la comunidad de los municipios de Cajamarca e Ibagué debido a los 
potenciales impactos negativos a nivel ecológico, social, económico, político y cultural en este territorio considerado despensa agrícola nacional y estrella hídrica regional.

La puesta en marcha de este proyecto tiene impactos directos que van más allá del territorio del municipio de Cajamarca, llegando a municipios como Piedras ubicado a varias decenas de kilómetros en donde se proyectó la ubicación de los sistemas de extracción del oro por lixiviación con cianuro y la ubicación de los depósitos de relaves o diques de colas que contendrían los cientos de millones de toneladas de material restante luego de la extracción. Esta situación llevó a que las comunidades de estos municipios recurrieran a diversas formas de manifestación que incluían marchas, mítines, audiencias públicas, cabildos abiertos, escenarios de formación ambiental comunitaria y Consultas Populares, la primera de ellas, llevada a cabo en el municipio de Piedras. La Consulta Popular, temática presentada en ese trabajo, es un mecanismo de participación ciudadana reconocida mediante la Ley 134 de 1994, la cual requiere de la participación de por lo menos la tercera parte de la población habilitada para votar en el municipio, departamento o el país, dependiendo su alcance territorial.

En Colombia se han realizado en total 37 consultas populares, entre ellas 10 sobre temas minero-energéticos y 27 sobre temas diversos (pertenencia municipal, modelo de paz, prohibición de fumigación con herbicidas, retiró de empresa sanitaria, creación de municipios y vinculación municipal de áreas metropolitanas, rechazo al involucramiento de la población civil en la guerra, día sin carro, creación de relleno sanitario, remodelación de infraestructura y ubicación de juegos de azar). El 51\% de las Consultas Populares que se realizaron sobre temas diversos no alcanzaron el umbral necesario de participación (tercera parte del censo electoral), razón por la cual no fueron procedentes, mientras que el 100\% de las Consultas Populares sobre temas minero-energéticos superaron el umbral y alcanzaron porcentajes de rechazo superiores al 95\%; de igual forma, el 90\% de las consultas superaron con creces la votación de los alcaldes electos en el periodo de realización de la Consulta, exceptuando el municipio de Tauramena.

La Consulta Popular de Piedras-Tolima, la primera realizada en Colombia sobre temas mineros, se efectuó el 28 de julio del 2013 y como proceso ayudó a potenciar el uso de estos mecanismos de participación por parte de las organizaciones ambientales y el primer gran revés que tuvo el proyecto minero La Colosa. La respuesta del alto gobierno frente a los resultados de la Consulta de Piedras fue enfática y con tonos de descalificación del proceso y 
los resultados. El ministro de Minas de la época, Federico Rengifo, manifestó que existen autoridades con la competencia del manejo del subsuelo de la Nación, entre los que destaca el Ministerio de Ambiente, las CAR, los distritos especiales y el Ministerio de Minas que por ley son "quienes con un estudio pueden excluir a un territorio de la minería. Los habitantes de los pueblos no pueden decidir; hay una reglamentación para hacerlo" (El Espectador, 2013).

Después del 29 de julio de 2013, en atención a los planteamientos de rechazo del gobierno nacional, las organizaciones sociales y ambientales tuvieron que implementar un sinnúmero de acciones y alianzas que les han permitido lograr que las consultas populares, al día de hoy, sean legales, constitucionales y puedan prohibir la minería. No olvidemos que los funcionarios locales, entre ellos alcaldes y concejales, que promovieron o dieron visto de conveniencia a los procesos de Consulta Popular sobre temas minero-energéticos fueron intimidados o amenazados previamente con inhabilidades disciplinarias por parte de la Procuraduría General de la Nación a través de oficios de advertencia. Al alcalde de Piedras, Arquímedes Ávila, la procuraduría le abrió una investigación preliminar que nunca procedió bajo el argumento que "podría estar incurriendo en extralimitación de funciones al promover en su municipio actividades en contra de proyectos mineros" (Ibid). Esta investigación se usó como precedente para amenazar a los alcaldes y concejales que se encontraban en sintonía con los movimientos socio-ambientales de defensa territorial.

La raíz de los contundentes resultados alcanzados después de acompañar la Consulta Popular de Piedras el Comité Ambiental decidió promover consultas en los municipios que componen la Cuenca Mayor del Río Coello; sin embargo, al tener dificultades para llevar a cabo las consultas en todos los municipios que conforman la Cuenca (Cajamarca, Ibagué, Rovira, San Luis, Espinal, Coello y Flandes), se decidió realizarlas solamente en los municipios de Espinal, Ibagué y Cajamarca.

En un primer momento, durante el año 2014 se realizaron todos los contactos con los alcaldes, pero solamente los mandatarios del Espinal y Cajamarca decidieron presentar la solicitud a los respectivos Concejos municipales con el propósito de obtener el visto bueno de esa corporación, el cual tiene un carácter obligatorio. Las dos iniciativas fueron hundidas por los cabildantes por amplia mayoría. Para el caso de Cajamarca la ciudadanía renovó 8 de los concejales que negaron con anterioridad la consulta y eligieron una mayoría de concejales a favor del proceso. Para el año 2016 los municipios de Ibagué y Cajamarca inician de nuevo el proceso de convocatoria.

La Consulta Popular de Ibagué fue presentada con 6 meses de antelación en relación a la de Cajamarca con el objetivo de tener tiempos disponibles para articular los esfuerzos y 
coordinar simultáneamente los dos procesos de defensa territorial, el del Comité Ambiental en Defensa de la Vida (Ibagué) y el Comité Ambiental y Campesino de Anaime y Cajamarca. Se implementaron Comités Promotores de las consultas populares con el propósito de integrar nuevos actores sociales, distintos a los sectores ambientalistas, dada la preocupación existente por el cumplimiento del umbral que garantiza el carácter vinculante o de obligatorio cumplimiento de los resultados.

El proceso de Ibagué fue presentado por el alcalde municipal y aprobado por el Concejo municipal con una diferencia de sólo un voto a favor; para el caso de Cajamarca el proceso fue de origen ciudadano, dado que el alcalde del municipio era de pensamiento prominero, razón por la cual el Comité Promotor se dispuso a recoger el 10\% de las firmas del censo electoral que se requiere para poder presentar la iniciativa ante la Registraduría Nacional de Colombia; así, en tan sólo 15 días se colectaron cerca de 5000 firmas, la votación del Concejo fue de 8 a favor y tres en contra.

Las consultas populares surtieron positivamente todos sus trámites y fueron aprobadas por el Tribunal Contencioso Administrativo del Tolima. En Ibagué la alcaldía definió una primera fecha de realización de la consulta para el 2 de octubre de 2016 que fue reprogramada para el 30 de octubre de 2016 dado que el gobierno nacional convocó para ese mismo día la votación del plebiscito por la paz. Producto de una tutela interpuesta por la Asociación Minera e Hidrocarburos del Tolima la Consulta Popular fue suspendida por intermedio de la Sección Cuarta del Consejo de Estado quien ordenó el 12 de octubre "suspender la Consulta Popular minera de Ibagué" mientras unifica y resuelve las tutelas interpuestas contra su desarrollo. El 7 de diciembre del mismo año, la misma Sección Cuarta del Consejo de Estado, reformula la pregunta original de la Consulta Popular y define la siguiente: ¿Está usted de acuerdo SÍ o NO que en el municipio de Ibagué se ejecuten proyectos y actividades mineras? Sobre el asunto hay que advertir que la alcaldía, en dialogo con el Comité Ambiental en Defensa de la Vida, decide apelar la decisión del Consejo de Estado en la medida que la Corporación se extralimitó en sus competencias al modificar la pregunta, la cual es potestad del Tribunal Contencioso Administrativo del Tolima.

En febrero de 2017 la Sección Quinta del Consejo de Estado acoge la solicitud de la alcaldía y manifiesta la incorrecta decisión de sus colegas de la Sección Cuarta al evidenciar que desbordaron sus competencias al sugerir una nueva pregunta señaló: "el fallador de primera instancia de tutela, desbordó sus competencias, al proponer una nueva pregunta, sin facultad para ello, apartándose de todos los debates políticos y jurídicos que fueron dados durante el trámite de la Consulta Popular, por ello consideraron que se debió determinar si era 
o no constitucional la pregunta que se pretendía hacer mediante la consulta popular, sin sugerir como hacerlo".

Finalmente, y dado que el Tribunal Contencioso Administrativo del Tolima decide mantener la pregunta ¿Está usted de acuerdo SÍ o NO que en el municipio de Ibagué se ejecuten proyectos y actividades mineras? La alcaldía, en acuerdo previo con el Comité Ambiental en Defensa de la Vida, decide cancelar el proceso, dado que no se puede afectar las familias que extraen material de arrastre del Río Combeima y los pequeños mineros que extraen oro de manera artesanal sin usar ningún químico contaminante en el municipio de Ibagué.

Las dificultades que se presentan en la Consulta Popular de Ibagué permitieron conocer de antemano algunos de los inconvenientes que se fraguarían contra la Consulta Popular de Cajamarca. En este sentido, así que de manera calcada se presentan las tutelas, en este caso la propia Anglogold Ashanti decide interponer una contra el proceso y la modificación de la pregunta. Al final, el Tribunal Administrativo del Tolima genera el mismo cambio en relación a la pregunta de la Consulta, con la diferencia que en este caso el Comité Ambiental y Campesino de Anaime y Cajamarca, junto a los promotores de la consulta popular, deciden continuar la consulta con la pregunta propuesta por esa Corporación. ¿Está usted de acuerdo Sí o NO que en el municipio de Cajamarca se ejecuten proyectos y actividades mineras?

En total participaron 6241 personas, de las cuales 6165 votaron NO a las actividades mineras dentro del municipio de Cajamarca y 76 votaron SÍ. La estrategia de la empresa y los defensores de las actividades extractivas fue promover la abstención, para ello registraron su respectivo comité ante la registraduría e implementaron una campaña de desinformación que trataba de descalificar la capacidad vinculante de las consultas populares frente a los proyectos mineros.

La Misión de Observación Electoral (MOE) denunció que con el objetivo de incentivar la abstención de la Consulta Popular de Cajamarca se estaba promocionando un paseo masivo a la ciudad de Buga para visitar la basílica del Señor de los milagros, justamente el mismo día de las votaciones; de igual forma se denunció que se tenía el plan de retener las cedulas de ciudadanía de un gran porcentaje de votantes, documento necesario para poder participar del proceso electoral, para lo cual "estarían pagando 200 mil pesos a los ciudadanos que entreguen su documento de identidad ese fin de semana para evitar su participación en la jornada democrática". En todas las casas del casco urbano del municipio se repartieron, por debajo de las puertas, paquetes de volantes que desde varios discursos 
promovían la abstención y descalificación del proceso de la Consulta Popular (ver figuras No. 4 y 5). Esos mismos argumentos eran divulgados por las emisoras más escuchadas. Para neutralizar estas acciones, se dispuso un grupo de trabajo que tuvo la responsabilidad de recorrer permanentemente el municipio para estar pendiente de la llegada de los buses que podían hacer el transporte masivo, se implementó una alerta generalizada con el propósito de detectar los lugares donde se podría estar recibiendo las cédulas para su retención y se estableció una estrategia de comunicaciones que permitió esclarecer algunas de las preocupaciones de la comunidad en relación a la consulta.

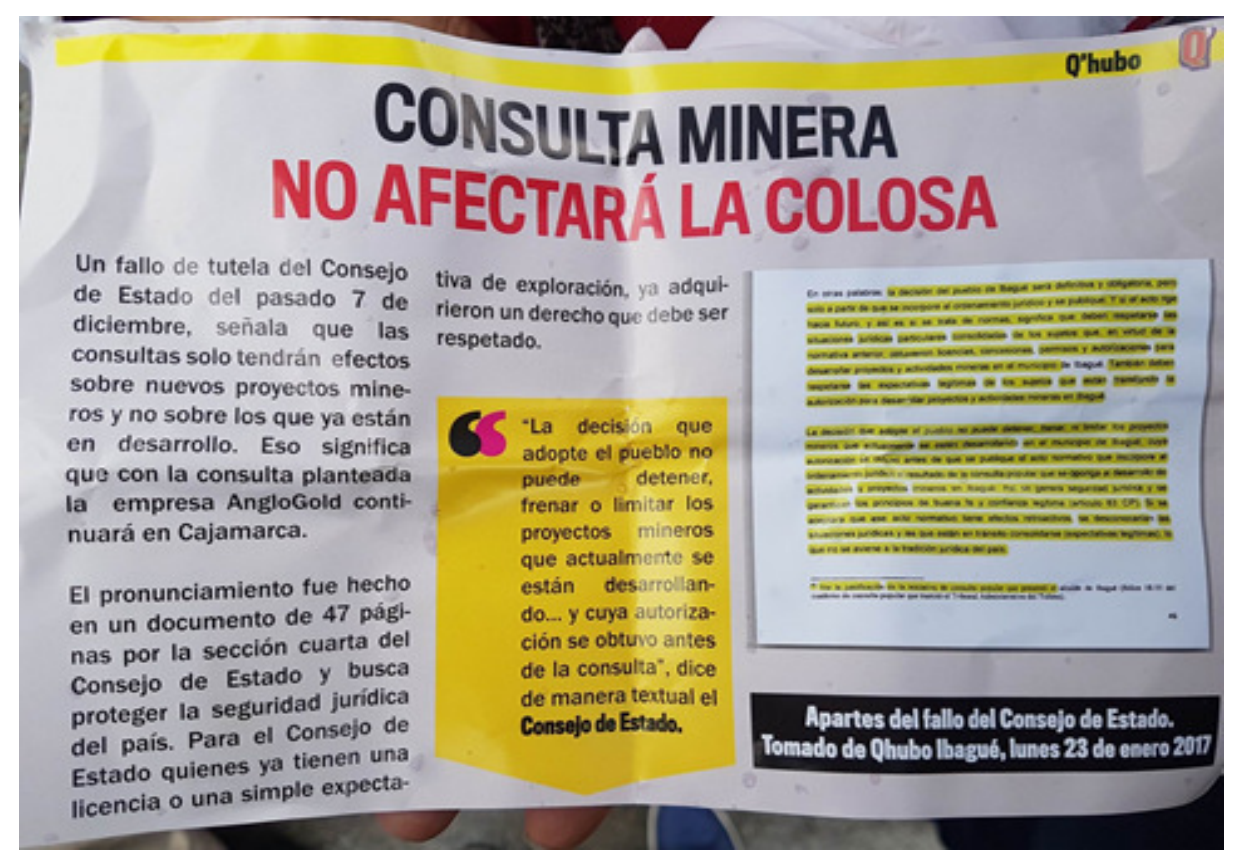

Figura 4. Volante con información falsa que descalifica el alcance vinculante de las consultas populares.

Fuente: Parra, 2019.

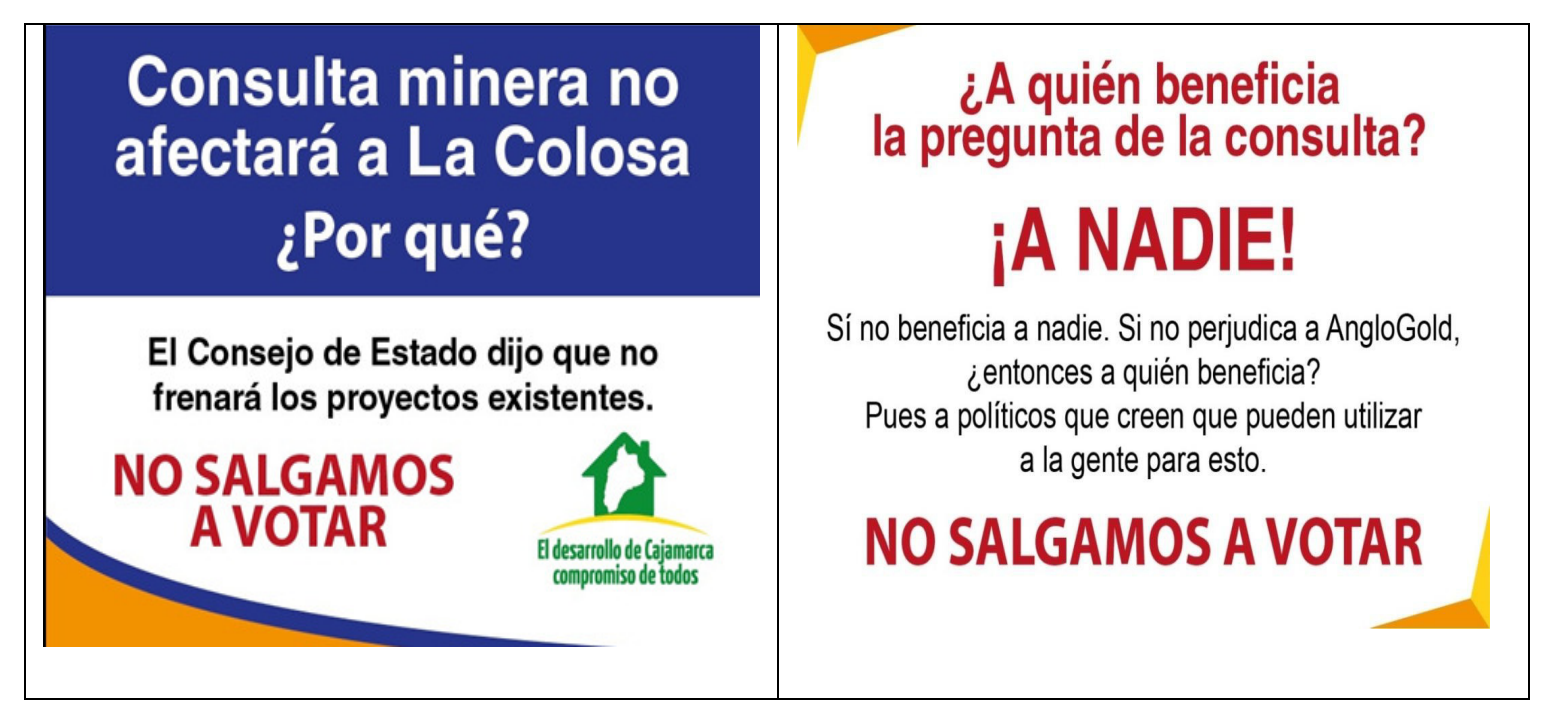


Figura 5. Volantes que repartieron por debajo de las puertas de las casas de los habitantes del casco urbano de Cajamarca.

Fuente: Parra, 2019.

Integrantes del equipo promotor denunciaron que la Registraduría Nacional del Estado Civil recortó de 36 a 18 el número de mesas aptas para la votación de la Consulta Popular, cuando 15 días antes, en la elección atípica del alcalde de Cajamarca, había instalado 36 mesas de votación, un proceso similar al de la consulta, en la medida que se utilizó un sólo tarjetón. El Comité Promotor manifestó su desconcierto por la disminución del número de mesas, "esto es un saboteo, es imposible que podamos votar en menos de dos minutos. El proceso requiere entregar la cedula, que el jurado busque el nombre del votante, que se entregue el tarjetón, se marque el NO, se firme y se le devuelva la cédula a los votantes. La Registraduría hace eso con el objetivo de evitar que logremos el umbral" (Torres, 2017 apud Parra, 2019). Para tratar de resolver el asunto, los comités ambientales tuvieron que realizar una entrega masiva de tarjetones didácticos con el propósito de familiarizar los votantes con el tarjetón de la consulta, se repartieron 15 mil volantes con la información. A pesar de todas estas estrategias, los resultados fueron adversos a la minería empresarial, sus aliados y defensores.

\section{LA DISPUTA LEGAL FRENTE A LAS CONSULTAS POPULARES}

Los resultados positivos que han obtenido las consultas populares frente al tema minero-energético -y el carácter vinculante de las mismas en términos legales- ha generado gran preocupación por parte del gobierno nacional y las empresas minero-energéticas, pues pese a que se han realizado en medio de condiciones desfavorables, dadas las desventajas comunitarias en parangón con la superioridad colosal de capacidades de las multinacionales y el gobierno nacional, los procesos y organizaciones socio-ambientales que se oponen al extractivismo han logrado ganar las votaciones y superar el umbral exigido por la Ley 134/94 que establece la normatividad que reconoce y regula los mecanismos de participación ciudadana.

Parte de la preocupación que tiene el gobierno y las empresas minero-energéticas radica en que los resultados o los efectos que legalmente tiene la Consulta Popular tienen un carácter vinculante. En relación a ello, en la página web de la Registraduría Nacional se puede leer: 


\begin{abstract}
Efectos de Consulta: Cuando el pueblo haya adoptado una decisión obligatoria, el órgano correspondiente deberá adoptar las medidas para hacerla efectiva. Cuando para ello se requiera una ley, una ordenanza, un acuerdo o una resolución local, la corporación respectiva deberá expedirla dentro del mismo período de sesiones y a más tardar en el período siguiente. Si vencido este plazo el Congreso, la asamblea, el concejo o la junta administradora local, no la expidiere, el Presidente de la República, el gobernador, el alcalde, o el funcionario respectivo, dentro de los tres meses siguientes la adoptará mediante decreto con fuerza de ley, ordenanza, acuerdo o resolución local, según el caso. En este caso el plazo para hacer efectiva la decisión popular será de tres meses. (Registraduría Nacional del Colombia, S.F apud Parra, 2019).
\end{abstract}

La lista de argumentos jurídicos, sociales, económicos y ambientales que soportan la Consulta Popular contra actividades mineras contaminantes ratifica la legalidad y legitimidad de estos procesos. Es decir, la Consulta Popular tiene un carácter vinculante o de obligatoriedad a la hora de identificar proyectos con impactos relevantes en el suelo y vocaciones productivas de los territorios. Pese a que las consultas populares se encontraban ajustadas a la normatividad constitucional, legal y jurisprudencial, el gobierno nacional y el gremio minero-petrolero implementaron una ofensiva para desconocer los mecanismos de participación ciudadana con el objetivo de limitar la voluntad popular y los resultados obtenidos en estos procesos democráticos. Teniendo en cuenta ello, el Comité Ambiental se dispuso a la tarea de fortalecer la incidencia internacional con el objetivo de defender la autonomía territorial y las consultas populares como mecanismos constitucionales que permiten resolver los conflictos socioambientales de manera democrática.

La incidencia del Comité Ambiental en Defensa de la Vida, junto a otros procesos colombianos y el acompañamiento internacional de la RIDH y FIAN, permitió que el Comité de Derechos Económicos, Sociales y Culturales de las Naciones Unidas le hiciera un llamado al gobierno nacional a respetar las consultas populares. El proceso consistió en dar a conocer informes paralelos a los que presenta el gobierno para la evaluación que hace las Naciones Unidas en Derechos Humanos. "Nos hemos reunido con más de 40 misiones diplomáticas y algunas de ellas han mostrado interés en hacerle recomendaciones al Estado de Colombia en el sentido que respete los resultados de las Consultas y que se abstenga de presentar proyectos de ley que modifiquen el carácter vinculante de las consultas" (Trujillo, 2018 apud Parra, 2019) .

Pese a que el Estado Colombiano tiene 18 meses para acoger e implementar las recomendaciones del Comité de Derechos Económicos, Sociales y Culturales, vimos cómo algunas de sus actuaciones estuvieron en contravía de las observaciones planteadas. El Ministerio de Hacienda negó la financiación de las consultas populares relacionadas con actividades extractivas y desconoció fallos judiciales como el del Tribunal Administrativo del 
Quindío que le ordenó al Ministerio disponer y destinar los recursos necesarios para llevar a cabo la Consulta Popular del municipio de Córdoba-Quindío. Por otro lado, el Ministerio de Minas se rehúsa a reconocer e implementar los resultados de las diez consultas populares que al día de hoy se han realizado en Colombia sobre actividades extractivas, entre ellas la de Cajamarca.

Las únicas instituciones del Estado que han reconocido la Consulta Popular de Cajamarca son el Concejo Municipal del municipio y la Corporación Autónoma del Tolima (ver resolución 1963 del 05 de julio de 2018). Pese a las recomendaciones de las Naciones Unidas y de las organizaciones socioambientales, la nueva Corte Constitucional, como la define el Movimiento Nacional Ambiental, dada la presencia de nuevos integrantes, efectuó la revisión del alcance de las Consultas Populares y profirió la Sentencia SU-095 de 2018, mediante la cual limitan el carácter vinculante de ese mecanismo de participación ciudadana en relación a las decisiones de materia minera y petrolera. A través de ese fallo se cercenan

\section{(...) derechos constitucionales como la autonomía territorial, la descentralización administrativa, la transparencia e imparcialidad, la copropiedad del subsuelo en cabeza de los municipios, la participación ciudadana, la facultad de las comunidades de decidir sobre sus propias formas de desarrollo, exacerbando el centralismo e imponiendo el extractivismo como política macroeconómica del país (Movimiento Nacional Ambiental, 2019 apud Parra, 2019).}

El fallo desconoce el principio democrático del Estado Social de Derecho, "la democracia ambiental, la paz territorial y los principios de precaución, no regresividad y rigor subsidiario al excluir a las comunidades locales y a los municipios de un mecanismo que les permitía de manera efectiva defender su territorio frente a actividades que generan graves afectaciones ambientales y sociales" (Movimiento Nacional Ambiental, 2019 apud Parra, 2019). Además de lo anterior, la Corte Constitucional a través de la Sentencia C-053/19 declaró la inconstitucionalidad del artículo 33 de la Ley 136/94, el cual contemplaba la obligatoriedad de realizar consultas populares frente a proyectos mineros, turísticos, entre otros, que generan cambios significativos en los usos del suelo. El argumento central de la decisión obedeció a que según la Corte esa competencia corresponde a una ley orgánica y no una ley ordinaria. Aunque el artículo 33 de la Ley 136/94 expresaba la obligatoriedad de realizar consultas populares frente a proyectos que afectaran los usos del suelo, es claro que el gobierno siempre desconoció la norma y los mandatos constitucionales.

La decisión de la Corte Constitucional esbozada en la sentencia SU 095/18 cambia por completo la línea jurisprudencial que reconocía la soberanía popular, la autonomía territorial y la democracia participativa. 
Ensino, Saúde e Ambiente - Número Especial, pp. 331-352, Junho. 2020

La decisión que acaba de tomar la nueva Corte evidencia la captura corporativa que ejercen las empresas extractivas sobre el estado colombiano (...) la Corte reversó fallos anteriores, desconoció sus propias consideraciones, profirió fallos regresivos en términos de Derechos Humanos e impone una reforma constitucional de facto de la mano del gobierno nacional en el que privilegia el interés económico de las empresas extractivas sobre los derechos de las comunidades (TOCORA, 2019 apud PARRA, 2019).

En palabras del Movimiento Nacional Ambiental (2019) estas decisiones ahondan la conflictividad social y ambiental, alejan la esperanza de la paz territorial, de la profundización de la democracia y la posibilidad de una sociedad con justicia social y ambiental. En términos de la solución al conflicto minero La Colosa podríamos decir que pese a la limitación de las consultas populares como un mecanismo de participación democrática y constitucional que podía ayudar a resolver la conflictividad socioambiental y fortalecer algunos de los principios y derechos fundamentales estructurales del Estado Social de Derecho Colombiano (autonomía territorial, participación ciudadana y derecho colectivo al ambiente sano), el fallo no debería tener carácter retroactivo y la decisión asumida por la comunidad debe ser respetada.

\section{CONCLUSIÓN}

Los conflictos socioambientales causados por proyectos mineros en Colombia cada vez cobran más fuerza. Las movilizaciones de los movimientos de defensa territorial han aumentado de manera significativa en los últimos años, sólo para el 2011 "se registraron no menos de 50 movilizaciones contra la minería, muchas de ellas impulsadas por organizaciones sociales que han ido consolidando una agenda de defensa de sus recursos naturales" (Pardo, 2011 apud Parra, 2019).

La resistencia al proyecto La Colosa, en Ibagué y Cajamarca ha tenido cierto éxito dada la capacidad de articulación, movilización, incidencia, aprendizaje y visibilización que las organizaciones socioambientales han logrado generar. Algunas de estas acciones, como la Consulta Popular han surgido producto del ejercicio de estudio, análisis, intercambios y diálogos que el Comité Ambiental en Defensa de la Vida (Ibagué) y el Comité Ambiental y Campesino de Cajamarca han implementado en conjunto con académicos y otros actores de defensa territorial, de escala nacional e internacional.

Como respuesta a la resistencia identificamos la estrategia de la empresa minera (Anglo Gold Ashanti) y de los defensores de las actividades extractivas de promover la abstención, además de implementar una campaña de desinformación que trataba de descalificar la capacidad vinculante de las Consultas Populares frente a los proyectos mineros. Otro punto de extrema relevancia es su modo de actuar delante de la actuación comunitaria, de postergar, cancelar y cambiar las preguntas de las Consultas. Los más poderosos actúan 
para desconocer los mecanismos de participación ciudadana con el objetivo de limitar la voluntad popular y los resultados obtenidos en estos procesos democráticos. En términos de comunicación, las empresas neoextrativistas, recurren a la producción y diseminación de volantes para comunicación y "educación" con informaciones falsas que representan la minería como algo positivo para el pueblo y las consultas como procesos sin legitimidad.

En la negociación, las transnacionales y el gobierno promueven la desmovilización, cooptación de sujetos, descredito en los procesos participativos, invisibilización de los beneficios que tendrá el grupo social más fuerte, ocultación de las informaciones acerca del emprendimiento contaminador, además de la minimización del valor de la vida.

Todas las estrategias, preocupaciones y actuaciones de las empresas y de las alcaldías firman las consultas populares como efectivas. Una acción popular política de fuerza mueve el sistema y provoca respuestas, lo que es un proceso de resistencia efectivo de las comunidades. Fueron muchas las dificultades que tuvieron que sortear las comunidades del municipio de Cajamarca para poder ganar la consulta, junto a la presencia por más de 10 años del proyecto en fase de exploración. Quizás este sea uno de los elementos que le dan relevancia nacional al proceso, saber que en medio de tanta adversidad es posible ganar, ya que las consultas populares frente al tema minero-energético han logrado ganar las votaciones y superar el umbral exigido por la Ley 134/94 para su aprobación. Además, cada Consulta ofrece aprendizajes para la próxima, la fortalece y motiva, como fue el caso de la Consulta Popular de Cajamarca e Ibagué, que se promovieron después de la de Piedras.

Las Consultas Populares están ajustadas a la normatividad constitucional, legal y jurisprudencial. Reconocemos que ellas movilizan en nivel nacional e internacional; difunden para más allá de los territorios los enlaces de Injusticia Ambiental; revelan las contradicciones del sistema capitalista; informan y forman los sujetos en lucha de resistencia a cerca de los procesos de extracción minero-energéticos; integran sujetos: movimientos sociales, ambientales, políticos y, en especial para nosotros, la universidad y los estudiantes de todos los niveles. La Consulta Popular busca ampliar la problematización del conflicto en los territorios y legitimar el posicionamiento político de las poblaciones afectadas. Provocando posicionamiento ante el deseo de apropiación empresarial desenfrenada. Por lo tanto, dicha herramienta no pretende neutralizar el conflicto. La propuesta es actuar dentro de este, buscando discutir la desigualdad socioambiental y promover la acción política colectiva.

Destacamos que nuestro trabajo parte del dialogo de saberes propuesto por la EABC, una integración del conocimiento académico con el saber comunitario. Resaltamos la descripción de la actuación de los movimientos sociales frente al conflicto de La Colosa como 
potencia para comprender el dialogo de saberes. En cada nueva acción se aprende a cerca de la experiencia de interactuar frente a las relaciones de poder de las estructuras sociales que se suponen hegemónicas y únicas en la relación sociedad-naturaleza. Con la disputa de poder descentrada de las decisiones del capital en los conflictos socioambientales las comunidades imprimen su posición contra la minería y con eso las empresas y el gobierno necesitan respuestas y medidas de mitigación, no apenas estrategias de silenciamiento.

Lo que emerge de la resistencia nos indica que la EABC que defendemos debe ir más allá de revelar a las comunidades las cuestiones ambientales y las posibilidades de un futuro sostenible, y aprender con las comunidades su forma de ser y actuar en diálogo con la naturaleza. Desde la Ecología Política desvelamos que el ecologismo parte desde los pobres con soluciones para la crisis socioambiental. Identificamos que las comunidades, muchas de las veces miradas como las responsables de los daños ambientales, son en general, las más afectadas por los problemas ambientales. Entonces, para plantear una EABC es urgente la praxis con las comunidades, mirar los conflictos desde sus necesidades y aprender con sus prácticas y formas de actuación popular.

\section{REFERENCIAS BIBLIOGRAFICAS}

ACSELRAD, Henri. Negociação e Mediação de Conflitos Socioambientais. Palestra proferida na Abertura do IX Encontro Tematico da 4'. Camara de Coordenação e Revisão do Ministerio Publico Federal, Brasilia. 2010.

DIETZ, K. Consultas populares mineras en Colombia: Condiciones de su realización y significados políticos. El caso de La Colosa. Colombia Internacional, (93), 93-117. 2018.

EL ESPECTADOR. 2013. Disponible en internet en: http://www.elespectador.com

ESCOBAR, Arturo. Sentipensar con la tierra: Nuevas lecturas sobre desarrollo, territorio y diferencia. Ediciones UNAULA. Medellín.184p. 2014.

LAYRARGUES, Philippe Pomier. Identidades da educação ambiental brasileira. Brasília: MMA. 2004.

LAYRARGUES, Philippe Pomier; LIMA, G. F. C. As macrotendências político-pedagógicas da educação ambiental brasileira. Ambiente \& Sociedade, São Paulo, v. 17, n. 1, mar. 2014.

LOUREIRO, Carlos Frederico. Educação Ambiental: Questões de vida. Cortez, São Paulo. 2019.

LEFF, Enrique. La Ecología Política en América Latina. Un campo en construcción. Rev. Polis, (Chile). 2(5): 125-145. 2003. Disponible en internet en: https://doi.org/DOI: $10.4000 /$ polis. 6871 Edito

MARTINEZ ALIER, Juan. Las Relaciones Entre La Economia Ecologica Y La Ecologia 
Politica. Rev.Ecológica y la Ecología política. 2010. Disponible en internet en: http://www.idea.unal.edu.co/eventos/2EEE/ponencias/Joan Martinez Alier1.pdf

MARTÍNEZ ALIER, J. Conflictos Ecológicos y Justicia Ambiental. Rev. Papeles de relaciones ecosociales y cambio global, 103, 11-27. 2008. Disponible en internet en: https://territoriosendisputa.wordpress.com/2014/09/03/conflictos-ecologicos-y-justiciaambiental-de-joan-martinez-alier-en-pdf/

MARTÍNEZ ALIER, J. El ecologismo de los pobres. Conflictos ecológicos y lenguajes de valoración. Editorial Icaria, (Barcelona). 368p. 2011.

MARTÍNEZ ALIER, Juan, \& ROCA JUSMET, J. Economía ecológica y política ambiental ( $3^{\mathrm{a}}$ edición). Ed. Fondo de Cultura Económica - Mexico. 2013.

MERLINSKY, G. Cartografías del conflicto ambiental en Argentina. Ed G. Merlinsky. (Buenos Aires).320p. 2013.

PARRA, Renzo Alexander Garcia. Proyecto minero La Colosa: Elementos desencadenantes del Conflicto Socioambiental, actores sociales en disputa y tensiones alrededor de la dimensión Social, Económica, Ecosistemica. (Maestría en Territorio, Conflicto y Cultura) - Facultad de Ciencias Humanas - Universidad Del Tolima, Tolima. 2019.

PELACANI, Bárbara. As lutas que educam na América Latina: A Educação Ambiental que emerge do conflito pela água em Cachoeiras de Macacu com um olhar desde a Colômbia. Dissertação (Mestrado em Educação) - Programa de Pós-Graduação em Educação, Universidade Federal do Estado do Rio de Janeiro, Rio de Janeiro. 2018.

PELACANI, Bárbara; OLIVEIRA, Carolina Alves; SÁNCHEZ, Celso. La educación ambiental de base comunitaria que emerge del conflicto con la represa hidroeléctrica de El Peñol, Colombia. Revista Perspectivas Educativas. Universidad del Tolima, Ibagué - Tolima, Colombia. 2018.

PÉREZ-RINCÓN, M. A. Conflictos ambientales en Colombia: actores generadores y mecanismos de resistencia. Rev. Ecología Política. (Colombia). 48: 76-82. 2010. Disponible en internet en:http://www.ecologiapolitica.info/?p=1980.

SANTOS, Milton. Por uma outra globalização - do pensamento único à consciência universal. Rio de Janeiro: Record. 2000.

SARRIA, J. A. V.; Pelacani, B.; Espinosa, G. M. F.; Renaud, D.; Pereira, C. S. La Educación Ambiental Comunitaria: Reflexiones, Problemáticas Y Retos. In: Kassiadou, A; Sánchez, C; Camargo, D; Stortti, M; Costa, R. (org.) Educação Ambiental desde el Sur. Macaé: Editora NUPEM. 2018.

TOLEDO, V. M. Metabolismos rurales: hacia una teoría económico-ecológica de la apropiación de la naturaleza. Revista Iberoamericana de Economía Ecológica. (Brazil). 7:1-26. 2008.

VERA, J. M., \& MORENO, É. A. El Tolima y la lucha por el territorio. Periferia Prensa Alternativa, (129), 12-13, 2017. Recuperado de

https://issuu.com/periferiaprensa/docs/edici_n_129_junio_-_julio_2017

VERA, J. M., et al. Atlas de Conflictos Ambientales del Tolima. (En preparación), 2019. 